Las Torres de Lucca. Revista internacional de filosofía política

ISSN-e: 2255-3827

\title{
El entramado neoconservador en América Latina. La instrumentalización de la ideología de género en las democracias contemporáneas
}

\author{
Juan Marco Vaggione
}

Recibido: 29-07-2020 / Aceptado: 20-10-2021 / Publicado: 30-01-2022

\begin{abstract}
Frente al avance de los derechos sexuales y reproductivos, se ha producido una reacción moral conservadora que, trascendiendo las fronteras entre lo religioso y lo secular, instaura nuevas formas políticas en América Latina. Uno de los principales emergentes de esta reacción es la consolidación del giro ideología de género como diagnóstico y amenaza para movilizar las creencias e instituciones religiosas en defensa de la vida y la familia. Precisamente, el propósito de este artículo es considerar las instrumentalizaciones de la ideología de género como una ventana analítica para identificar las principales dimensiones públicas del neoconservadurismo en los países de la región. La lucha contra la ideología de género se consolidó como una de las facetas más visibles de la politización moral conservadora y a través de su observación pueden comprenderse distintos tramos de la articulación entre el conservadurismo religioso y la política contemporánea
\end{abstract}

Palabras clave: conservadurismo moral; derechos sexuales y reproductivos; religión y política.

\section{[en] The Neoconservative Thread in Latin America. The Instrumentalization of Gender Ideology in Contemporary Democracies.}

\begin{abstract}
Faced with the advance of sexual and reproductive rights, a conservative moral reaction has emerged that, transcending the frontiers between the religious and the secular, establishes new political forms in Latin America. One of the main elements of this reaction is the consolidation of the turn gender ideology as a diagnosis and threat, used to mobilize religious beliefs and institutions in defense of values such as life, family and freedom. The purpose of this article is to consider the instrumentalizations of gender ideology as an analytical window to identify the main public dimensions of neoconservatism in the countries of the region. The fight against gender ideology is consolidated as one of the most visible facets of moral politicization and, through its observation, the articles considers different aspects of the articulation between religious conservatism and contemporary politics.
\end{abstract}

Keywords: Moral conservatism; Sexual and reproductive rights; Religion and politics.

Cómo citar: Vaggione, J. M. (2022). El entramado neoconservador en América Latina. La instrumentalización de la ideología de género en las democracias contemporáneas. Las Torres de Lucca. Revista internacional de filosofía política, 11(1), 51-64. https:// dx.doi.org/10.5209/ltdl.79437

Referir a la politización de las creencias religiosas en defensa de una moral sexual conservadora como un fenómeno novedoso en América Latina sería borrar las influencias que el catolicismo primero y otras tradiciones con posterioridad tuvieron en la sociedad y en el Estado. Estas influencias han sido determinantes en las formas de regular el orden sexual ya que las normas legales y morales tendieron a estar fuertemente imbuidas por (sino imbricadas en) la moral cristiana. Más acertado sería afirmar que, al menos en parte, esta politización es, en la actualidad, el resultado de una temporalidad abierta por el accionar los movimientos feministas y LGBTQI; temporalidad que si bien difiere entre los países de la región pone en cuestión el cimiento religioso, a veces poco visible, sobre el que se estructura el orden sexual.

Los movimientos feministas y LGBTQI legitimaron paradigmas alternativos para la regulación de la sexualidad que, entre otras cuestiones, profundizan el proceso de secularización de las normas legales. La demanda por los derechos sexuales y reproductivos es, también, una demanda por nuevos pactos democráticos respecto al papel de lo religioso en la política. Por ello, no es sorprendente que distintos sectores vinculados a lo religioso reaccionen en defensa de valores tradiciones que consideran amenazados por las demandas de estos movimientos. Se produce un proceso de politización de lo religioso y de lo moral (muchas veces indistinguibles)

Consejo Nacional de Investigaciones Científicas y Técnicas; Universidad Nacional de Córdoba, Argentina.

Correo electrónico: juanvaggione@yahoo.com.

ORCID: https://orcid.org/0000-0002-7983-6884

Las Torres de Lucca. 11 (1), 2022: 52-64 
que da lugar al surgimiento y consolidación de un activismo conservador que busca recristianizar el orden público. Si bien es un activismo que tiene continuidades con el papel histórico de lo religioso, inaugura estrategias e instrumentaliza enmarques argumentales que desafían las formas de comprensión de la política democrática.

Uno de los principales emergentes de este renovado conservadurismo religioso, o neoconservadurismo, es el giro ideología de género como diagnóstico del momento y como amenaza al orden social. Es un giro que surge frente al avance de los derechos sexuales y reproductivos en la década de los noventa y comienza a expandirse, de forma paulatina, para ser en la actualidad una de las principales estrategias para movilizar valores morales tradicionales. Sirvan de ejemplos la conformación de la Campaña Con mis Hijos no te Metas en Perú (2016), el rechazo a través de un plebiscito a la firma del acuerdo de paz en Colombia (2016) o el discurso de Bolsonaro al asumir la presidencia en Brasil (2019). Estos ejemplos, que tienen en común el llamado a luchar contra la ideología de género, evidenciaron la capacidad de actores conservadores de movilizar la ciudadanía en base a una agenda moral y religiosa centrada en la defensa de la vida y la familia.

La lucha contra la ideología de género se consolidó como una de las facetas más visibles de la politización moral conservadora y a través de su análisis pueden comprenderse distintos tramos de la articulación entre el conservadurismo religioso y la política contemporánea. Precisamente, el propósito de este artículo es considerar la instrumentalización de la ideología de género como una ventana analítica para identificar dimensiones públicas del neoconservadurismo en América Latina. La primera sección presenta algunos estudios que analizan la politización conservadora con el objetivo de identificar los principales abordajes y énfasis sobre la temática. La segunda considera la emergencia y expansión del giro ideología de género como parte de la interlocución entre la jerarquía católica y el autodenominado activismo provida y profamilia. La última sección analiza algunas instrumentalizaciones de la lucha contra la ideología de género que permiten comprender las principales modulaciones del neoconservadurismo en la región.

\section{La reacción moral conservadora como objeto de estudio}

Lejos de desaparecer o de replegarse, la defensa (con viejos y nuevos lenguajes) de la moral anudada a una concepción reproductivista y matrimonial reemergió y comenzó a expandirse en contextos de incertidumbre y de creciente desconfianza y desinterés respecto de la política. El paulatino reconocimiento de los derechos sexuales y reproductivos no logró resolver las principales tensiones que construyen al orden sexual, sino, en todo caso, impulsó a que estas se canalicen y emerjan de otras formas y con diversas intensidades. El conservadurismo moral renueva sus estrategias y argumentos en reacción al avance de derechos vinculados a la educación sexual, las parejas del mismo sexo, la identidad de género o el aborto. Este avance implicó, como se señala en otros trabajos (Vaggione, 2005; 2020), una politización reactiva ${ }^{2}$ que inaugura una etapa diferente en la movilización de las creencias e instituciones religiosas en defensa de una moral universal que se considera acechada por el pluralismo ético que legitima el avance de estos derechos.

Esta politización conservadora tiene un fuerte impacto y deja al descubierto que no era pura reactividad destinada a la extinción sino, por el contrario, que se estaba frente a una reacción articulada de un proyecto de restauración moral. Aunque se han incrementado los estudios para comprender este proceso, es una agenda aún en desarrollo y prueba de ello es la diversidad de rótulos que se utilizan para nombrar (y por tanto, definir) al fenómeno. Términos como conservadurismo, antiderechos, derecha religiosa, derecha cultural y fundamentalismo son algunos de los que más circulan en las publicaciones; muchas veces usados en plural para evidenciar su heterogeneidad o acompañados por el prefijo neo para marcar sus aspectos más actuales. Si bien estos términos apuntan a (y desde) diferentes aristas, todos buscan dar sentido a la reemergencia en la defensa de valores tradicionales en un contexto de creciente diversidad en las prácticas sexuales y de mayor autonomía en las formas de identificación con lo religioso.

Aunque ningún concepto está exento de limitaciones, el de neoconservadurismo utilizado en este artículo permite comprender que, si bien la defensa de una moralidad sexual conservadora atraviesa la historia de la región, su reemergencia contemporánea requiere de enmarques analíticos y normativos renovados para captar múltiples adaptaciones y cambios (Vaggione y Machado, 2020). Reconociendo que es un concepto multívoco, en este artículo se lo utiliza, en línea con Brown (2006), en tanto racionalidad política moral que produce modelos de subjetividad y pone en juego matrices de inteligibilidad que ordenan lo decible y producen criterios de veridificación determinados. El neoconservadurismo es más que la conformación de una política moral en defensa de valores tradicionales como la vida desde la concepción o la familia heteronormativa, es también un proyecto de estatalidad y de ciudadanía que es apropiado e instrumentalizado por distintos sectores. Precisamente, estas instrumentalizaciones se vinculan al carácter dinámico y cambiante del neoconservadurismo.

El concepto de politización reactiva de lo religioso es utilizado desde el Programa en Derechos Sexuales y Reproductivos de la Facultad de Derecho de la Universidad Nacional de Córdoba para dar cuenta del conservadurismo moral. 
En los últimos años se intensificaron las publicaciones que buscan desentrañar esta reemergencia conservadora no solo a través de artículos dispersos sino también de compilaciones y eventos específicos (Facchini y Sívori, 2017; Carranza, 2020; Sales y Ricardo, 2019; Vigoya y Rondón, 2017; Biroli y Caminotti, 2020; Corrêa y Kalil, 2020; Almeida y Toniol, 2018). Estas publicaciones han sofisticado la comprensión del fenómeno y, desde diferentes enmarques teóricos, iluminan aristas del conservadurismo moral como fenómeno político contemporáneo. Pueden, en principio, identificarse tres tipos de abordajes distinguibles por motivos expositivos de los cuales surgen los principales sentidos y alcances que se dan a la racionalidad moral conservadora en las sociedades contemporáneas. Es necesario aclarar que estos abordajes son propuestos como una forma de ordenar los estudios existentes y los principales énfasis interpretativos de la ola conservadora.

En primer lugar, los estudios sobre el género y la sexualidad, de algún modo pioneros en la temática, enfatizan la agenda heteropatriarcal en esta resurgencia conservadora. Los solapamientos y articulaciones entre academia y activismo (incluso muchas veces la indistinción entre ambos campos) favorecieron que organizaciones feministas y LGBTQI impulsaran gran parte de las primeras investigaciones sobre la temática. Una serie de estudios, a veces presentados como mapeos regionales, identificaron los actores que, en general, motivados por sus creencias religiosas se movilizan en defensa de la vida desde la concepción y de la familia heteronormativa. ${ }^{3}$ Sin desconocer a las jerarquías eclesiales, estos trabajos dan cuenta, entre otros aspectos, de la conformación de un activismo autodenominado provida o profamilia como un pilar constitutivo del neoconservadurismo. Si bien este abordaje suele priorizar las especificidades de los diferentes países, rescata al avance neoconservador como parte de un proceso transnacional (Morán Faúndes, 2015).

Estos estudios señalan la diversidad de los argumentos utilizados por el activismo provida y profamilia ya que además de motivaciones religiosas o morales circulan razones científicas, legales o bioéticas (entre otras) (Vaggione, 2005; 2020). La reactivación conservadora también es abordada a través de la intensificación de ciertos estereotipos o fobias generadas frente al creciente pluralismo en las prácticas e identidades sexogenéricas (Zamberlein, 2015; Miskolci y Campana, 2017; Bárcenas, 2021). En particular, el concepto de pánico moral, que se retoma más adelante, sirve de anclaje para comprender la radicalidad de algunas reacciones tanto en el plano social como en el político. En los últimos años, comenzó a analizarse el fenómeno bajo el nombre de movimientos o campañas antigénero (Corrêa y Kalil, 2020; Corrêa, 2018). Estas campañas se dan a nivel nacional y transnacional como, por ejemplo, la Organización de Estados Americanos. De manera similar a lo que sucede en Europa (Kuhar y Paternotte, 2017), la oposición al género se convierte en un "aglutinante simbólico" para diferentes sectores políticos (Kováts y Poim, 2015).

Otro abordaje relevante es impulsado por los estudios de la religión (Machado, 2018; Carranza 2020; Luna; 2017; Almeida, 2017). Estos estudios tienen uno de sus principales focos en la relación entre lo religioso y lo político (tanto a nivel analítico como normativo) razón por la cual no es sorprendente que propongan renovadas lecturas sobre el impacto de las creencias e instituciones religiosas en la reemergencia moral conservadora (Almeida, 2017). Este abordaje tiende a complejizar a las religiones como actores públicos y a acentuar la diversidad existente al interior del campo religioso. Una contribución es considerar el crecimiento de las iglesias evangélicas, sobre todo las pentecostales y neopentecostales, como una dimensión determinante en el proceso de remoralización de la política en temas vinculados a la familia y la sexualidad (Machado, 2018).

Otro énfasis de este abordaje es tematizar la laicidad como lente para comprender el accionar público de las religiones en defensa de un orden moral tradicional (Blancarte, 2008). ${ }^{4} \mathrm{Si}$ bien se reconoce que la laicidad no requiere (necesariamente) la privatización de lo religioso, la tendencia más generalizada es considerar la politización de lo religioso como un riesgo para las democracias de la región. La laicidad funciona, entonces, como un instrumental analítico y normativo para comprender la politización religiosa conservadora como parte de una arremetida a la necesaria separación entre el Estado y la iglesia. Otro aporte de este abordaje, que excede el propósito de este artículo, es rescatar las potencialidades emancipatorias de las creencias religiosas incluso en relación a la libertad y diversidad sexual evitando reducir lo religioso a sus expresiones más conservadoras. Se han intensificado los trabajos que evidencian la permeabilidad del campo religioso a las teorías, identidades y posicionamientos provenientes de los movimientos feministas y LGBTQI. ${ }^{5}$

El tercer abordaje llega al análisis de la reacción moral conservadora por su interés en la emergencia de la denominada nueva derecha (también llamada derecha radical o populismo de derecha entre otros conceptos). ${ }^{6}$ La derecha ha sido, en general, más afín a defender concepciones tradicionales sobre la familia por ello, no es sorprendente, que las nuevas manifestaciones de derecha incorporen como parte de sus plataformas el

La mayoría de los estudios pioneros en este sentido pueden consultarse en las páginas web institucionales de las principales organizaciones feministas que los impulsaron: Católicas por el Derecho a Decidir, Sexuality Policy Watch o Promsex.

Existen distintas publicaciones en este sentido. Algunas de ellas están compiladas en la Colección Jorge Carpizo, ver: http://catedra-laicidad.unam. mx/jorge-carpizo y también en la página de la Red Iberoamericana de Libertades Laicas ver: http://www.libertadeslaicas.mx

Se mencionan, sólo a título de ejemplos, los numerosos debates teológicos que reconstruyen las tradiciones religiosas desde lecturas feministas y/o queer.

Sin desconocer las múltiples restricciones y debates en torno al concepto, suele referirse a nuevas derechas para caracterizar un posicionamiento político que, además de adherirse al neoliberalismo, defiende una moral tradicional en el contexto de democracias más consolidadas. Esta es una generalización básica ya que existen distintos tipos de expresiones de derecha y extrema derecha en diferentes regiones que exceden al objetivo de este artículo. 
rechazo a temas como la legalización del aborto, el reconocimiento de derechos para las personas LGBTQI o la implementación de la educación sexual en los colegios. El impacto de estos derechos en la agenda pública también implicó que la defensa de los valores tradicionales se convirtiera en propuestas electorales de diferentes partidos y candidatos. En particular, la defensa de los valores familiares es considerada una contracara de las reformas neoliberales, ya que la familia pasa a ser la principal proveedora de educación, salud y cuidado por oposición al retraimiento del estado frente a sus funciones sociales (Cooper, 2019; Biroli, 2020). En el plano normativo, este abordaje considera que en la articulación entre racionalidades neoconservadoras y neoliberales residen los procesos de desdemocratización por el que atraviesan distintas sociedades contemporáneas (Brown, 2020; Biroli, 2019).

Este tipo de abordaje también repara en la influencia de lo religioso sobre la conformación de nuevas configuraciones de derecha. El impacto del catolicismo en la región implicó que la derecha (partidaria o no) tenga como baluarte político la defensa de la moral cristiana, aspecto que se intensifica en las nuevas derechas y también se alimenta por la politización de las iglesias evangélicas conservadoras. Al vínculo histórico entre representantes de la derecha política y la jerarquía católica se agregan otros actores que aportan nuevos recursos y capitales simbólicos en un contexto regional de interrupción del pretendido monopolio de la Iglesia Católica sobre el campo moral. Por ejemplo, se han señalado las afinidades entre la teología de la prosperidad de ciertas corrientes evangélicas y el neoliberalismo como racionalidad política (Burity, 2020). También las denominadas nuevas espiritualidades han sido vinculadas a las nuevas manifestaciones de derecha y de centro derecha (Souroujon, 2019). Esta centralidad dada a lo religioso hace que incluso se utilice el término de derecha cristiana para referirse al surgimiento de nuevas expresiones partidarias en la región.

Más allá de sus énfasis, los tres abordajes coinciden, como puede observarse, en la centralidad que tiene lo religioso en la rearticulación del conservadurismo moral. Lo religioso ha mantenido su influencia en la regulación del cuerpo sexuado más allá de los procesos de secularización social y política, por ello no es sorprendente que el neoconservadurismo sea, en gran medida, el producto de la politización de las jerarquías eclesiales y de la movilización de las creencias religiosas. Si bien no es una dinámica novedosa adquiere, como lo señalan los abordajes, nuevas modulaciones frente al cambio de época impulsado por los movimientos feministas y LGBTQI. En una región como América Latina, la politización conservadora es un fenómeno entrelazado (incluso indistinguible) de la politización de lo religioso.

Sin embargo, el neoconservadurismo excede la caracterización de ser un fenómeno religioso. La adaptación a la temporalidad abierta por los movimientos feministas y LGBTQI en las formas de defender los valores tradicionales implicó una transformación del neoconservadurismo como fenómeno político. Sin dejar de ser un fenómeno religioso, si es que alguna vez lo fue de forma exclusiva, el neoconservadurismo es también un fenómeno secular y cualquier caracterización que reduzca los actores, argumentos o valores defendidos a un campo o al otro es, inevitablemente, incompleta. Como se señaló previamente, las agrupaciones autodenominadas provida o profamilia ocupan un lugar destacado en la defensa de la agenda neoconservadora. Otro ejemplo referido es el uso de argumentos científicos, legales o bioéticos por parte de actores religiosos en la defensa pública de su doctrina, proceso denominado secularismo estratégico (Vaggione, 2005).

Incluso la propia dicotomía religioso-secular ha mostrado sus limitaciones teóricas para captar la política sexual contemporánea lo que empuja a repensar los presupuestos desde los que se lee (y construye) al neoconservadurismo. Existen una serie de críticas que cuestionan esta dicotomización y las limitaciones analíticas que de ella se coligen. Talal Asad (2003), William Connolly (1999) o Joan Scott (2018) son algunos de los autores cuyos trabajos pueden considerarse pioneros porque, entre otras cuestiones, corren el foco hacia lo secular como la parte menos reflexionada de la dicotomía. Asad, un precursor en este tipo de críticas, consideró al secularismo como un mito de la modernidad y afirmó que la investigación sobre lo religioso requería, inevitablemente, revisar las concepciones existentes sobre lo secular y sobre el secularismo en tanto doctrina política. Connolly, por su parte, desdibuja las fronteras que la modernidad erigió entre argumentos religiosos y seculares y propone una concepción postsecular de lo público que se caracterice por un pluralismo profundo. Finalmente, Scott (2018) interrumpe la construcción de la modernidad secular como un momento de mayor liberalización y considera, al contrario, que la construcción de lo secular trajo aparejada la instauración de la desigualdad de género.

La regulación del orden sexual pone en evidencia las limitaciones de lo secular como oposicional a lo religioso. Por esto, es necesario reflexionar sobre las distintas reconfiguraciones que exceden una visión dicotómica (Jakobsen y Pellegrini, 2004; Saez, 2016). Como lo afirma Marey en relación a América Latina, los "liberalismos secularistas y postsecularistas no pueden procesar ni en la teoría ni en la práctica la reordenación política de las iglesias cristianas conservadoras (católicas y evangélicas) en nuestra región" (Marey, 2020:47). De algún modo, son las fronteras, los bordes, entre lo religioso y lo no religioso lo que debe debatirse (Quack, 2014) para permitir un acercamiento más acabado al fenómeno del neoconservadurismo.

Se propone en las próximas secciones analizar la emergencia, consolidación e instrumentalizaciones del giro ideología de género como ventana analítica para comprender el neoconservadurismo a partir de las articulaciones entre dimensiones religiosas y no religiosas. 


\section{La expansión de la ideología de género: entre la jerarquía y el activismo provida}

El origen de la expresión ideología de género se ubica en la década de los noventa como parte del diagnóstico hecho por activistas provida (pro life) al reconocimiento de los derechos reproductivos durante las Conferencias de Población y Desarrollo de las Naciones Unidas — particularmente las de El Cairo (1994) y de Beijing (1995) - . Suele considerarse el libro The Gender Agenda (O'Leary, 1997) pionero en la caracterización de la agenda de género (bajo el rótulo de feminismo radical) como ideológica porque no representaría el interés de la mayoría de las mujeres. Este trabajo (y el de quienes escriben hoy contra la ideología de género) afirma que la diferenciación entre el género como una construcción sociopolítica y el sexo en tanto diferencia biológica es la base ideológica y distorsiva del feminismo. Otro aspecto que también subsiste hasta hoy es denunciar la estrategia del feminismo radical de penetrar los organismos internacionales para luego imponer su agenda en distintas regiones a través de la cooptación del discurso de los Derechos Humanos (O’Leary, 1997).

El giro ideología de género adquirió carnadura en los intercambios y las articulaciones entre el activismo provida y la jerarquía católica. Si bien en la década de los noventa el Vaticano utilizaba la expresión "cultura de la muerte" para englobar las demandas vinculadas al aborto, la anticoncepción o la eutanasia (Juan Pablo II, 1995), comenzó paulatinamente a adoptar "ideología de género". El Cardenal Ratzinger primero como prefecto de la $\mathrm{Fe}$ y luego como Papa tuvo un papel relevante en esta adopción. Su experiencia en Alemania durante la década de los ochenta lo había expuesto a las críticas feministas (Case, 2019), que él consideraba como pura ideología que niega la perspectiva defendida por la Iglesia Católica, para la cual "la diferencia y la complementariedad físicas, morales y espirituales están orientadas a los bienes del matrimonio y al desarrollo de la vida familiar" (Catecismo de la Iglesia Católica, 1995, § 224).

La incorporación de la ideología de género como diagnóstico y amenaza se plasma en los documentos del Vaticano y en las declaraciones públicas de su jerarquía desde esos años hasta la actualidad. Aunque mencionada con anterioridad (Cf. Familia y Derechos Humanos, 1999; Familia, Matrimonio y Uniones de Hecho, 2000), en el año 2003 se produce un intento de definición al incluirla en el Lexicón de términos ambiguos y discutidos sobre familia, vida y cuestiones éticas (Consejo Pontificio para la Familia, 2004). El propósito de esta publicación es identificar y aclarar términos que son utilizados engañosamente. Según el prólogo, escrito por el Cardenal López Trujillo (quien en ese momento presidía el Pontificio Consejo de la Familia), la expansión de la referencia al género tiene como propósito crear "nuevos derechos" que convierten "de forma inmediata delitos en derechos" y construyen una "verdad política" a través de negar la ley natural. La llegada de Bergoglio como Papa Francisco en el 2013, para algunos un giro progresista, continúa con un posicionamiento similar respecto a la ideología de género. En su Exhortación apostólica postsinodal Amoris laetitia Francisco afirma que la ideología de género

Presenta una sociedad sin diferencias de sexo, y vacía el fundamento antropológico de la familia. Esta ideología lleva a proyectos educativos y directrices legislativas que promueven una identidad personal y una intimidad afectiva radicalmente desvinculadas de la diversidad biológica entre hombre y mujer (Francisco, 2016).

Si bien le dio su propio énfasis, sobre todo considerar a esta ideología en conexión con la colonización (TELAM, 2016), Francisco no modificó la posición doctrinaria o política de la iglesia respecto a los temas vinculados al género y la sexualidad (Véase Sgró Ruata y Vaggione, 2017, donde se amplía este argumento).

El abordaje más completo y sistemático hasta la fecha producido por la Iglesia Católica es una publicación de la Congregación para la Educación Católica (2019). La peculiaridad de este documento es que distingue entre "la ideología del gender y las diferentes investigaciones llevadas a cabo por las ciencias humanas." Previamente, toda referencia al género como teoría era considerada ideológica. Con este documento se abre una distinción entre un uso acertado y una versión ideológica de "género". El uso acertado coincide con la perspectiva vaticana de la complementariedad que, según el documento, debe ser la base para la "adecuación del derecho positivo a la ley natural, según la cual la identidad sexual es indiscutible, porque es la condición objetiva para formar una pareja en el matrimonio". La perspectiva ideológica, en cambio, busca "imponerse como un pensamiento único que determine incluso la educación de los niños", caracterización que se hace citando a Francisco. De manera similar a otros términos, como la laicidad o incluso el feminismo, el Vaticano diferencia entre una versión correcta (o buena) con la que la institución dialoga (incluso coopta) y una versión radical que debe confrontarse por considerarla una amenaza. En vez de posicionarse como antigénero, se presenta como contrario a las teorías sobre el género que rotula como ideológicas y dentro de las cuales engloba a todas las interpretaciones, menos a las que reafirman la complementariedad que es la postura del Vaticano.

Un punto a destacar de esta breve reconstrucción es la preocupación por el derecho como arena en la cual debe resistirse en avance de la ideología de género. El término surge en reacción al avance legal de los movimientos feminista y LGBTQI y se utiliza, mayoritariamente, como un enmarque político para

Se mantiene la palabra gender ya que es la utilizada en versión en español del documento probablemente como una forma de destacar lo foráneo de esta ideología. 
resistir o revertir este avance. Precisamente, se considera que esta ideología es parte de lobbies que "quieren imponer a naciones soberanas "nuevos derechos' humanos, como los 'derechos reproductivos" (Pontificio Consejo para la Familia, 1998). Esta ideología no solo busca crear una "revolución cultural e ideológica" sino también, como afirma la Congregación para la Educación Católica (2019), una "revolución jurídica" ante la cual hay que defender los "derechos fundamentales de la persona, en particular a aquel de la libertad de pensamiento, conciencia y religión". Si bien el término surgió en reacción a la descriminalización del aborto y, por tanto, en defensa de la vida desde la concepción, comenzaron a incorporarse otras demandas legales como parte de la expansión de esta ideología. En general, todos los denominados derechos sexuales y reproductivos son resistidos por reflejar esta ideología, en particular el reconocimiento a las parejas del mismo sexo, la implementación de programas de educación sexual y la legitimación de la identidad de género autopercibida.

En América Latina el giro ideología de género también se expandió como resultado de la articulación entre la jerarquía católica y el activismo provida. Debido a la influencia del catolicismo en la región, no es sorprendente que haya habido un uso temprano. En el año 1998, la Conferencia Episcopal de Perú publicó un folleto donde advierte sobre la existencia de una ideología detrás del concepto de género y afirma que, por su impacto, "toda la moral queda librada a la decisión del individuo y desaparece la diferencia entre lo permitido y lo prohibido". Este documento también hace referencia a un proceso de infiltración ya que "los proponentes de esta ideología usan sistemáticamente un lenguaje equívoco para poder infiltrarse más fácilmente en el ambiente, mientras habitúan a las personas a pensar como ellos". Otro momento relevante fue en el 2007 cuando la V Conferencia General del Episcopado Latinoamericano (CELAM, 2007) incluye la ideología de género "entre los presupuestos que debilitan y menoscaban la vida familiar" y provocan "modificaciones legales que hieren gravemente la dignidad del matrimonio, el respeto al derecho a la vida y la identidad de la familia" (Documento Conclusivo de Aparecida, 2008).

El activismo provida en la región tuvo un rol central en la expansión e instrumentalización de la ideología del género. Estos activistas publicaron trabajos y participaron en encuentros nacionales y regionales con el propósito de divulgar los riesgos del avance de la ideología de género y la necesidad de defender la vida y la familia (Morán Faúndes, 2019). Un pionero fue Jorge Scala, abogado y activista antiaborto ligado al Opus Dei, quien comenzó a publicar sobre la temática en los primeros años del siglo XXI. Para este autor, la ideología de género "niega por principio, la naturaleza de las cosas y de las personas" y utiliza "una táctica de "lavado de cerebro"'. Si bien publicados en Argentina, sus trabajos han tenido distribución e impacto regional (siendo incluso alguno de ellos traducidos al portugués). Al igual que otros activistas, Scala considera que de triunfar esta ideología no existirían el matrimonio, la familia o la diferencia entre varón y mujer, lo que generaría un "colapso de la misma sociedad". Como toda ideología, no busca la verdad sino la conquista de voluntades para utilizarlas con un fin espurio (Scala, 2001).

Un impulso determinante en la masificación del término en la región es su apropiación por parte de sectores evangélicos conservadores. Si bien el campo evangélico es diverso, los sectores más restrictivos en temas de moral sexual lo adoptan y adaptan como diagnóstico de las principales amenazas al orden social. El crecimiento de las iglesias pentecostales y neopentecostales amplió las bases sociales del neoconservadurismo y, por tanto, propulsó la lucha contra la ideología de género en la región. Si bien estas iglesias al principio no se inmiscuían en la política, con los años comienzan a tener una mayor actividad pública y, en particular, el rechazo de los derechos sexuales y reproductivos se convierte en una prioridad para algunos de sus líderes (Machado, 2015). Sin desconocer la heterogeneidad del campo evangélico, parte de su jerarquía religiosa lidera la oposición a los derechos sexuales y reproductivos por considerarlos parte de una agenda contra la familia.

Las alianzas y movilizaciones conjuntas entre católicos y evangélicos conservadores, impensables décadas atrás, se han habilitado en la lucha conjunta contra la ideología de género. La construcción de un enemigo externalizado, un afuera constitutivo (Mouffe, 2002), en los movimientos feministas y LGBTQI permite diseñar una identidad común (un nosotros) que emerge por una relación antagónica (más o menos fantasmal) en la cual la ideología de género ocupa uno de esos polos. Así, la ideología de género permite desplazar la defensa de los valores católicos a valores universales e inalterables y da lugar a articulaciones que tienen en común la defensa de la vida desde la concepción y la familia tradicional. Como ha sido propuesto, el giro ideología de género funciona como un significante vacio (Mayer y Sauer, 2017) a través del cual se agrupan actores que posponen sus diferencias frente a una amenaza compartida.

A pesar de que esta construcción antagónica parece homogenizar al polo moral conservador, existen tensiones y diferencias, algunas de las cuales se visibilizan en las formas en que se usa la ideología de género. Hay acuerdo en ubicar a los movimientos feministas y LGBTQI como los principales enemigos; sin embargo, existe una tensión sobre la conexión entre estos movimientos y otras corrientes ideológicas. En términos generales puede afirmarse que mientras la jerarquía del Vaticano tiende a considerar al neoliberalismo como una de las causas de la expansión de esta ideología, el activismo provida, al menos en América Latina, considera al marxismo como la principal explicación. Si bien en uno de los primeros documentos se menciona al "resurgir de nuevas expresiones de un socialismo de inspiración marxista" (Consejo Pontificio para la Familia, 1999), el Vaticano vincula la expansión de la ideología de género con la profundización de la defensa de la libertad 
individual y, explícitamente, con el neoliberalismo. Por ejemplo, se menciona que "la ideología de 'gender' ha encontrado en la antropología individualista del neoliberalismo radical un ambiente favorable" (Pontificio Consejo para la Familia, 2000) o se conecta la ideología de género con la defensa de las libertades individuales ya que "lo que vale es la absoluta libertad de autodeterminación y la elección circunstancial de cada individuo en el contexto de cualquier relación emocional" (Congregación para la Educación Católica, 2019).

Las apropiaciones desde el activismo provida, al contrario, tienden a enfatizar la conexión entre la ideología de género y el marxismo. Scala afirma que esta ideología es utilizada por "marxistas, feministas, homosexuales" con el propósito de obtener distintos privilegios. Por ello, considera a los teóricos de la revolución sexual asociados con la Escuela Crítica de Frankfurt como uno de los basamentos de la ideología de género. Otros difusores del término con impacto en la región, como Nicolás Márquez y Agustín Laje (2016), profundizan esta conexión. Laje afirma que la ideología de género amalgama el feminismo radical y el homosexualismo ideológico y es "una de las principales pantallas del neomarxismo" (p.9). Ante la falta de una clase revolucionaria, el marxismo clásico, según Laje, "abre paso de una lucha de clases a una lucha por la cultura (neomarxismo)", de la que son parte las feministas radicales (López Marina, 2017). El feminismo fue utilizado por el marxismo "en el marco de una declarada batalla cultural, al punto tal que terminaron afirmando, valga la paradoja, que la mujer no existe" (Laje, 2016, p. 109).

\section{Usos e instrumentalizaciones de la ideología de género}

Si bien las influencias cristianas matrizan la definición de la ideología de género, sus instrumentalizaciones políticas inauguran diversos campos de sentidos y de acción. Esta sección presenta algunos usos del término que permiten comprender la diversificación del neoconservadurismo como fenómeno contemporáneo. En primer lugar, se consideran dos de los principales valores que se politizan en reacción al avance de la ideología de género: la verdad y la libertad. La traducción de estos valores en términos legales es una de las principales estrategias neoconservadoras en el intento de recristianizar el orden social. En segundo lugar, se analiza el procedimiento de partidización de la lucha contra la ideología de género. Aunque esta lucha surge, como se presentó, de la interacción entre jerarquía eclesial y activismo provida, en los últimos años comenzó a ser parte de la propuesta programática de partidos y candidatos políticos.

\section{La naturaleza bajo amenaza: régimen de veridicción}

La lucha contra la ideología de género tiene como uno de sus principales objetivos defender las leyes de la naturaleza, lo biológico, como basamento del derecho. La agenda de los movimientos feministas y LBGTQI es considerada como una distorsión de estas leyes, ya que es una construcción ideológica que falsea la verdad. Este uso del término articula una política de la verdad, un régimen de veridicción (Foucault, 2007, pp. 50) que establece una antinomia entre lo falso en tanto ideológico (los argumentos feministas y LGBTI) y lo verdadero (la defensa de una moral objetiva y universal que invoca las leyes de la naturaleza como su fundamento). Así, la lucha se presenta como una cruzada contra la falsedad, la mentira y distorsión de las epistemologías y prácticas feministas y prodiversidad sexual. La denuncia de la ideología de género como distorsión de los Derechos Humanos es también argumentada por el Vaticano en las Naciones Unidas ( $C f$. Consejo Pontificio para los Laicos, 2011).

En general los documentos y declaraciones que denuncian la ideología de género buscan "desenmascarar" mentiras vinculadas a los derechos sexuales y reproductivos (Scala, 2001). Para ello, se priorizan los argumentos científicos y los centros académicos, muchos de ellos de corte confesional. ${ }^{8}$ Incluso ya se organizaron Congresos Internacionales como un foro para debatir las "consecuencias políticas y jurídicas de la ideología de género." Por ejemplo, la convocatoria del I Congreso Internacional sobre la ideología de género en el año 2011 organizado por la Universidad de Navarra.

Afirmar que la ciencia es un dispositivo de disciplinamiento y control de los cuerpos no parece ser una novedad para los estudios sobre la sexualidad; tal vez lo novedoso sea que el propio campo religioso es una usina directa de producción de razonamientos científicos en oposición a los derechos sexuales y reproductivos. En vinculación con el aborto, por ejemplo, se intensifican los argumentos genetistas para demostrar el inicio de la vida humana desde la concepción (Luna, 2013). Así, los sectores conservadores asumen que la aparición de una célula con una nueva identidad genética marcaría la aparición de una nueva vida distinta de la del padre y la madre. A su vez, se potencian la circulación de imágenes y ecografías para humanizar el feto (imágenes que en distintas oportunidades distorsionan más que representan). Otro ejemplo son los argumentos que apelan a la ciencia para reproducir discursos patologizantes frente a la identidad de género que proponen alternativas

En Argentina, al igual que en otros países de la región, la Universidad Austral (vinculada al Opus Dei), la Pontificia Universidad Católica de Argentina o la Fraternidad de Agrupaciones Santo Tomás de Aquino (Fasta). 
psiquiátricas, incluso quirúrgicas, de normalización o terapias "psicológicas" de reconversión sexual de la homosexualidad (Brito da Gama, 2019). Incluso un documento oficial del Vaticano hace referencia a este tipo de intervenciones afirmando que "en el caso de la indeterminación sexual, es la medicina la que interviene para una terapia" (Congregación para la Educación Católica, 2019).

Como se observa en estos ejemplos, los argumentos se mueven en un espectro que va desde publicaciones académicas o informes universitarios a la defensa de terapias e intervenciones médicas que han sido rechazadas por la propia comunidad científica en defensa de los derechos humanos. Si bien algunos de estos argumentos se alinean con lo que se considera ciencia, en otros casos reflejan argumentos discriminatorios y fuera de lo que puede considerarse científico. Esta oposición neoconservadora entre ciencia e ideología tiende a despolitizar (Morán Faúndes y Peñas Defagó, 2013) e incluso desmoralizar al conflicto. Más allá del debate sobre si estos argumentos son o no científicos, importa señalar que el neoconservadurismo traslada su disputa al régimen de veridicción en tanto "conjunto de reglas que permiten con respecto a un discurso establecer los enunciados que pueden caracterizarse en él como verdaderos y falsos" (Foucault, 2007, p. 51).

\section{La libertad amenazada: política del miedo}

La politización del miedo suele caracterizar los debates sobre la sexualidad ya que son momentos en los cuales se potencia el pánico moral y se canalizan las ansiedades vinculadas a distintos problemas sociales (Rubin, 1993). Mientras que en Europa es en general el tema de la inmigración, en el caso de América Latina suelen vincularse a la inseguridad ciudadana o a la crisis económica y política por la que atraviesan en general los países. El término de ideología de género se ancla, precisamente, en esta politización ya que convoca a luchar y a resistir un modelo autoritario que pretende imponerse de formas engañosas en la población. Es frecuente observar en documentos y declaraciones públicas que las demandas de los movimientos feministas y LGBTQI no solo contradicen las reglas de la naturaleza, sino que incluso buscan horadar las creencias religiosas, la existencia de la familia y el orden social mismo.

Esta politización del miedo, además de incentivar la violencia simbólica (Bárcenas, 2021), apela a la defensa de la libertad como un valor fragilizado por el avance de la ideología de género. Debido al basamento cristiano del neoconservadurismo, la libertad religiosa y de conciencia tienen un lugar destacado en la reacción conservadora. Se politiza una construcción oposicional entre libertad sexual y libertad religiosa y de conciencia por la cual el reconocimiento de la primera implica, necesariamente, la vulneración de las otras dos. Por un lado, la defensa de la libertad religiosa se transforma en una estrategia compartida por los sectores católicos y evangélicos conservadores. Esta libertad, otrora vulnerada por los privilegios de la Iglesia Católica, se reinscribe por ambos sectores frente al secularismo radical, expresión utilizada por Benedicto XVI, que se asocia a la agenda feminista y prodiversidad sexual. La politización de la libertad religiosa parece invertir la fórmula: en vez de reducir los privilegios de la Iglesia Católica, se busca hacerlos extensivos a otras tradiciones religiosas, particularmente de corte evangélico. Por otro lado, la libertad de conciencia, surgida en protección del pacifismo, se utiliza como estrategia para entorpecer, incluso bloquear, el acceso a la salud sexual y reproductiva (Alegre, 2009; Deza, 2014). A lo largo de la región se redefine la objeción de conciencia de ciudadanos y profesionales como estrategia que promueve la defensa de la libertad frente a leyes vigentes, lo que pone en riesgo el acceso a los derechos sexuales y reproductivos.

Otra libertad que se construye amenazada por la ideología de género es la de los progenitores a tomar decisiones sobre la vida de sus hijos e hijas. El neoconservadurismo considera que esta ideología se impone a través de un "adoctrinamiento" a las personas más indefensas que potenciaría la necesidad de su protección y tutela. Un ejemplo en este sentido es la Campaña "Con mis hijos no te metas", originada en Perú en el 2016, que se extendió por la región, tiene entre sus consignas la frase "no homosexualices a nuestros hijos" y utiliza los colores celeste y rosa para marcar simbólicamente la diferencia biológica entre niño y niña. Así, la democratización de la familia aparece como uno de los principales problemas; como lo afirma otra de sus consignas: "No quiero familias democráticas. Quiero una familia de Verdad" (Peker, 2018). En el campo jurídico, esta estrategia se traduce en la necesidad de fortalecer el instituto de la patria potestad, en tanto conjunto de derechos y obligaciones de los padres sobre sus hijos no emancipados. Se refuerza un paradigma adultocéntrico de la familia y se rechazan los derechos progresivos de niños, niñas y adolescentes que habilitan, entre otras cuestiones, el acceso a los anticonceptivos y educación sexual sin la aprobación de los progenitores como requisito obligatorio.

La instrumentalización de estas libertades permite también observar el entramado religioso-no religioso que caracteriza al neoconservadurismo. La defensa de la libertad religiosa es una de las estrategias priorizadas, sobre todo por las jerarquías eclesiales conservadoras que consideran los derechos sexuales y reproductivos como un riesgo para la práctica de las creencias religiosas. Pero también se politizan libertades que no se vinculan (al menos de forma directa) con lo religioso: por un lado, la objeción de conciencia se presenta como salvaguarda para la protección de un derecho individual, pero se utiliza en rechazo de los derechos sexuales y reproductivos y en defensa de una moral objetiva y universal; por otro lado, se busca fortalecer la libertad de 
los progenitores como forma de consolidar una definición de la familia en la cual el adulto conserva el poder de decisión sobre aspectos de las vidas de sus hijos-as.

\section{Partidización de la lucha contra la ideología de género}

Otra posibilidad que abre la lucha contra la ideología de género es inscribir la defensa de un orden sexual desde un posicionamiento antipolítico. Como ha sido señalado, la movilización de una ideología que dice no serlo es parte del fenómeno contemporáneo de la antipolítica (Romano y Parra, 2018). Denunciar al otro como ideológico permite posicionarse por fuera de la política y, de este modo, encarnar una propuesta alineada con el creciente desencanto poblacional con la política. Como surge de las encuestas, este desencanto se evidencia en la desconfianza generalizada hacia las instituciones, el decrecimiento de la insatisfacción con la democracia y el crecimiento de los denominados indiferentes al tipo de régimen, entre otros indicadores. Según Latinobarómetro (2018), en los últimos años se ha producido un deterioro en el apoyo a la democracia que descendió de un $61 \%$ en el 2010 a un $48 \%$ en el 2018; en conexión con esto también bajó la satisfacción con la democracia de un $44 \%$ en el año 2008 a un $24 \%$ diez años después mientras que las personas que se consideran indiferentes frente al tipo de régimen aumentaron en el mismo período de un $16 \%$ a un $28 \%$.

En los últimos años, la lucha contra la ideología de género (pretendidamente antipolítica) comenzó a partidizarse trascendiendo a la sociedad civil en tanto arena que permitió su consolidación. Las temáticas vinculadas a la familia, la educación o la sexualidad siempre fueron clivajes partidarios; sin embargo, adquieren nuevas modalidades y expresiones frente a los impactos de los movimientos feministas y LGBTQI. Estos movimientos lograron inscribir sus demandas en la sociedad política, razón por la cual no es sorprendente que la politización conservadora también busque partidizar su agenda. Si bien la utilización de la ideología de género por parte de líderes partidarios es un fenómeno reciente, en algunos países de la región es parte de las políticas gubernamentales. En Brasil, por ejemplo, en el año 2103 la referencia a la ideología de género ingresó en los debates parlamentarios. Estas referencias se intensificaron en el período 2015-2017 (Teixeira, 2019) y tuvieron su auge cuando Bolsonaro, como presidente, convierte su prohibición en una prioridad de su gestión.

Se proponen tres tipos de partidos que son más proclives a incluir esta lucha en sus candidaturas y plataformas (Vaggione y Morán Faúndes, 2021). En primer lugar, y sin desconocer que la lucha contra la ideología de género ha sido apropiada por líderes "progresistas", 9 son los partidos de derecha (rótulo con numerosas limitaciones) los que tienden a ser más receptivos a la defensa de una moral sexual alineada al cristianismo conservador. A ello se agrega que, como se mencionó previamente, en América Latina, el activismo provida ha tendido a asociar la ideología de género con el marxismo cultural y la izquierda; asociación que potencia su apropiación por parte de sectores de derecha. Así como los partidos de izquierda (o centro izquierda) suelen ser más proclives a incluir los derechos sexuales y reproductivos en sus plataformas, los de derecha, al contrario, movilizan los valores vida, familia y libertad o, incluso la lucha contra la ideología de género en búsqueda de apoyo electoral.

En segundo lugar, los partidos religiosos o confesionales son también un canal propicio para la incorporación de la ideología de género como diagnóstico y amenaza. Sin desconocer la existencia de partidos y/o candidaturas alineadas con el catolicismo, son los partidos de corte evangélico los que cambiaron el mapa político de la región. Como señala Casanova (1994), la Iglesia Católica dejó de promover la conformación de partidos políticos como forma de evangelización social. La incorporación de la lucha contra la ideología de género en el campo evangélico conservador (descrito previamente) produce su inclusión en algunos partidos evangélicos como forma de rechazo a los diferentes derechos vinculados al género y la sexualidad. Algunos de estos partidos comienzan a conformarse en la década de los ochenta y se potencian como parte de la reacción a los movimientos feministas y LGBTQ (Machado, 2021) con una agenda fuertemente conservadora en temas de moral sexual. Los partidos evangélicos han crecido en distintos países, llegando en algunos contextos a obtener importantes resultados electorales, particularmente en los países con mayor crecimiento de creyentes evangélicos.

Una tercera alternativa de partidización de la ideología de género, por el momento incipiente, son los partidos o candidaturas que tienen como principal, incluso única, propuesta política la defensa de la vida desde la concepción y de la familia tradicional. Como sucede con otros movimientos sociales, los líderes del activismo provida y profamilia traspasan a la arena política, sea a través de la creación de partidos que exclusivamente defienden esta agenda (single-issue party), partidos municipales o vecinales (para cuya conformación suelen exigirse menos requisitos formales), sea a través de la inscripción de sus candidaturas dentro de otros partidos

Suelen mencionarse los ejemplos de Correa en Ecuador o de Tabaré Vazquez en Uruguay que, de modos diferentes, podrían ser considerados líderes progresistas que han defendido públicamente un posicionamiento moral conservador. Incluso Rafael Correa se manifestó explícitamente en contra de la ideología de género afirmando que "no es teoría, es ideología ... son barbaridades que no resisten el menor análisis y que destruyen la base de la sociedad que sigue siendo la familia convencional" (Correa, 2014). 
políticos. Estos partidos y candidaturas buscan capitalizar, con dispares resultados, al conjunto de ciudadanos que priorizan la defensa de los valores tradicionales al momento de decidir su votación.

Estos tres procesos de partidización ponen en escena una estrategia más agresiva del conservadurismo moral contemporáneo: la prohibición o forclusión del género de las políticas públicas. En distintos países comenzaron a presentarse proyectos de leyes, en general por partidos como los previamente identificados, que tienen como propósito proscribir una serie de palabras asociadas a los movimientos feministas y LGBTQI para combatir la ideología de género. Estos proyectos suelen indicar expresamente las palabras que deben excluirse del ordenamiento jurídico y de las políticas públicas tales como: enfoque de género, enfoque de equidad de género, enfoque de igualdad de género, violencia de género, equidad de género, igualdad de género, expresión de género o identidad de género. Como ejemplos se pueden mencionar: el Proyecto de ley 3610/2018 en Perú que pretende excluir "del ordenamiento jurídico y las políticas públicas todo término que haga referencia a la ideología de género" (Congreso de la República de Perú, 2018); la Iniciativa 5272 en Guatemala que establece la prohibición, en colegios públicos y privados, de programas que incluyan la "diversidad sexual y la ideología de género" o "enseñar como normales las conductas distintas a la heterosexualidad" (Congreso de la República de Guatemala, 2017). Incluso en algunos países, como Brasil, existen propuestas legislativas en este sentido que llegan a plantear la criminalización de las personas que promueven la ideología de género (ver Luna, 2017). Si bien por el momento la aprobación de estos proyectos no se ha generalizado, existen ejemplos en los cuales a través de regulaciones oficiales se prohíbe expresamente la promoción de la ideología de género. Por ejemplo, en Paraguay, en el año 2107, la resolución número 29.664 del Ministerio de Educación y Ciencias prohibió "la difusión y la utilización de materiales impresos como digitales, referentes a la teoría y/o ideología de género".

Estos tres tipos de partidos (no completamente distinguibles) fungen como defensores públicos de una moral definida como única, universal y, por tanto, inalterable. Sus candidaturas y propuestas buscan captar el apoyo de ciudadanos identificados con valores morales tradicionales a través de la instrumentalización, entre otras cuestiones, de la lucha contra la ideología de género. De este modo, a las tres vertientes que confluyen en la defensa de la racionalidad neoconservadora previamente mencionados (sectores conservadores católicos, evangélicos y activistas provida/profamilia) se agregan actores de la sociedad política, complejizando al fenómeno. Este proceso de partidización también evidencia cómo las articulaciones y continuidades entre derecha religiosa, derecha secular y activismo provida trasvasan la dicotomización religioso-secular.

\section{Conclusiones}

El principal objetivo del artículo ha sido aportar a la comprensión del neoconservadurismo como fenómeno político contemporáneo. La defensa de los valores vida o familia, al adaptarse a la temporalidad abierta por los movimientos feministas y LGBTQI, adquiere nuevas configuraciones que evidencian la necesidad de repensar la reconfiguración de la política moral conservadora. Para ello, se indagaron algunos usos e instrumentalizaciones de la lucha contra la ideología de género que dejan ver las distintas vertientes que confluyen en la reemergencia moral conservadora. En los entrelazamientos de estas vertientes se articula la racionalidad moral neoconservadora que emerge, con intensidades cambiantes, en los países de América Latina.

Un aspecto que surge del análisis son las limitaciones de la dicotomización entre lo religioso y lo secular para comprender las principales dinámicas y valores que se movilizan contra la ideología de género. No puede negarse que, al menos en América Latina, la politización moral conservadora se conecta, en su matriz y contenidos, a lo religioso. Es, en muchos sentidos, un proyecto de recristianización frente al denominado secularismo radical que se asocia con esta ideología. Sin embargo, esta politización es más que una traducción en términos seculares ya que implica, podría decirse, una transformación de la política conservadora en sí misma.

Por un lado, el enmarque que propone la lucha contra la ideología de género trasciende el campo de lo religioso, incluso de lo moral, y se plantea como resistencia al proyecto totalitario asociado con los derechos sexuales y reproductivos. Los derechos sexuales y reproductivos, en tanto proyecto ideológico, se consideran parte de un adoctrinamiento que comienza por los niños y niñas en tanto los sectores más permeables y tienen como propósito final la destrucción misma de la familia. Se piensa a este como proyecto que distorsiona la verdad inscrita en las leyes de la naturaleza y legitima una serie de derechos a través de mentiras y distorsiones. Se pone en juego, entonces, un modelo de veridicción que debe defenderse para reestablecer no solo el orden sexual sino también el orden social.

Por otro lado, la lucha contra la ideología de género pone en escena una serie de alianzas (con mayor o menor estabilidad) de actores pertenecientes al campo religioso, a la sociedad civil y a la sociedad política. Si bien el término se acuña en la interacción entre la jerarquía católica y el activismo provida, luego se expande y es instrumentalizado por distintos actores que integran esta lucha con otras agendas políticas. Al mismo tiempo, los valores que se defienden en reacción a la ideología de género entrelazan dimensiones religiosas, morales y legales. Sin desconocer la impronta religiosa de estos valores, su juridificación (su inscripción en términos 
legales) habilita usos que trasvasan lo religioso y que se caracterizan por la imbricación (incluso indistinción) entre ambos polos de la dicotomía. Además de la vida y la familia, la defensa de la libertad adquirió un rol protagónico ya que se considera vulnerada, de modos diferentes, frente al avance de los derechos sexuales y reproductivos.

Finalmente, es cada vez más frecuente la incorporación de la lucha contra la ideología de género en los partidos políticos, particularmente aquellos que suelen caracterizarse como nueva derecha. Se expande la apropiación de esta lucha ya que se inscribe como propuesta electoral con el propósito de movilizar y representar a aquellos sectores de la población (más o menos numerosos) que se perciben amenazados por el pluralismo (legal y moral) que caracteriza las prácticas y decisiones sexuales en las sociedades contemporáneas. Esta partidización de la lucha contra la ideología de género evidencia la afinidad o incluso indeterminación entre el neoconservadurismo como racionalidad moral y el neoliberalismo como racionalidad económica.

La comprensión del neoconservadurismo como una racionalidad política contemporánea requiere, entonces, pensar (desde) los intersticios y articulaciones entre lo religioso y lo no religioso. Más que una dicotomía, hay que considerar una cartografía compleja de yuxtaposiciones, donde la diferenciación de actores y argumentos de forma dicotómica se complica o, incluso, imposibilita. Sin desconocer las formas en que lo religioso matriza al neoconservadurismo, es también necesario analizarlo como un fenómeno sociopolítico (como un proceso de evangelización secular) que desestructura las fronteras mismas entre lo religioso y lo no religioso.

\section{Referencias bibliográficas}

Alegre, Marcelo (2009). Opresión a conciencia: La objeción de conciencia en la esfera de la salud sexual y reproductiva. Seminario en Latinoamérica de Teoría Constitucional y Política. Papers, 66. https://digitalcommons.law.yale.edu/ yls_sela/66

Almeida, Ronaldo (2017). A onda quebrada: evangélicos e conservadorismo [La ola quebrada: evangélicos y conservadurismo]. Cadernos Pagu, 50, 1-27.

Almeida, Ronaldo y R. Toniol (Eds.). (2018). Conservadorismos, fascismos e fundamentalismos: análises conjunturais [Conservadurismos, fascismos y fundamentalismos: análisis coyunturales]. Unicamp. https://doi. org/10.7476/9788526815025

Asad, Talal (2003). Formations of the secular: Christianity, Islam and modernity [Las formaciones de lo secular: Cristianismo, Islam y modernidad]. Stanford University.

AWID (2008). Miradas compartidas: las y los activistas por los derechos de las mujeres definen los fundamentalismos religiosos. https://www.awid.org/es/publicaciones/miradas-compartidas-las-y-los-activistas-por-los-derechos-de-lasmujeres-definen-los

Bárcenas Barajas, Karina (2021). La violencia simbólica en el discurso sobre la 'ideología de género': una perspectiva desde la dominación simbólica a través del pánico moral y la postverdad. Intersticios Sociales, 21 (marzo): 125-150. http://www.intersticiossociales.com/index.php/is/article/view/319.

Biroli, Flávia (2019). A reação contra o gênero e a democracia [La reacción contra el género y la democracia]. Nueva Sociedad, número especial em Português, 76-87.

Biroli, Flávia (2020). Gênero, "valores familiares" e democracia [Género, "valores familiares" y democracia]. En Flávia Biroli, Maria das Dores Campos Machado, Juan Marco Vaggione (Eds.), Gênero, neoconservadorismo e democracia. Disputas e retrocessos na América Latina (pp. 135-187). Boitempo.

Biroli, Flávia y Caminotti, Mariana (2020). The conservative backlash against gender in Latin America [La reacción conservadora contra el género en América Latina]. Politics \& Gender, 16, 1-38.

Blancarte, Roberto (2008). Sexo, religión y democracia. Temas de Hoy.

Brito da Gama, Maria Clara (2019). Cura Gay? Debates parlamentares sobre a (des)patologização da homossexualidade [¿Cura gay? Debates parlamentarios sobre la (des)patologización de la homosexualidad]. Sexualidad, Salud y Sociedad. Revista Latinoamericana, 31, 4-27. https://doi.org/10.1590/1984-6487.sess.2019.31.02.a

Brown, Wendy (2006) American nightmare: Neoliberalism, neoconservatism, and de-democratization [La pesadilla americana: neoliberalismo, neoconservadurismo y des-democratización]. Political Theory, 34(6), 690-714.

Brown, Wendy (2020) En las ruinas del neoliberalismo. El ascenso de las políticas antidemocráticas en occidente. Tinta Limón.

Burity, Joanildo (2020). ¿Ola conservadora y surgimiento de la nueva derecha cristiana brasileña? la coyuntura postimpeachment en Brasil. Ciencias Sociales y Religión/ Ciências Sociais e Religião, 22(00), e020015. https://doi. org/10.20396/csr.v22i00.

Campos Machado, Maria das Dores (2015). Religião e política no Brasil contemporâneo: uma análise dos pentecostais e carismáticos católicos [Religión y política en el Brasil contemporáneo: un análisis de los pentecostales y de los carismáticos católicos]. Religião \& Sociedade, 35(2), 45-72. https://doi.org/10.1590/0100-85872015v35n2cap02

Campos Machado, Maria das Dores (2018). Religion and moral conservatism in Brazilian politics [Religión y conservadurismo moral en la política brasileña]. Politics and Religion Journal, 12(1), 55-77. 
Carranza, Brenda (2020). Presentación. Erosión de las democracias latinoamericanas: el ascenso político de los cristianos. Ciências Sociais E Religião, 22(00). https://doi.org/10.20396/csr.v22i00.13752

Casanova, José (1994). Public religions in the modern world [Religiones públicas en el mundo moderno]. University of Chicago.

Case, Mary Ann (2019). Trans formations in the Vatican's war on 'gender ideology' [Trans formaciones en las guerras del Vaticano sobre la 'ideología de género']. Signs: Journal of Women in Culture and Society, 44(3), 639-664. https:// doi.org/10.1086/701498

Catecismo de la Iglesia Católica (1995). https://www.vatican.va/archive/catechism_sp/p3s2c2a6_sp.html

Conferencia Episcopal Peruana (1998). La ideología de género. Sus peligros y alcances. https://www.aciprensa.com/ controversias/genero.htm

Congregación para la Educación Católica (2019). “Varón y Mujer los Creó.” Para una vía de diálogo sobre la cuestión del gender en la educación. https://www.vatican.va/roman_curia/congregations/ccatheduc/documents/rc_con_ ccatheduc_doc_20190202_maschio-e-femmina_sp.pdf

Congreso de la República de Guatemala (2017). Iniciativa Nro. 5272 que dispone aprobar Ley para la Protección de la Vida y la Familia. https://www.congreso.gob.gt/detalle_pdf/iniciativas/66\#gsc.tab=0

Congreso de la República de Perú (2018). Proyecto de Ley Nro. 3610 que promueve la adopción de la perspectiva de igualdad entre mujeres y hombres y excluye del ordenamiento jurídico y las políticas públicas todo término que haga referencia a la ideología de género y a cualquier otro que atente contra la igualdad entre mujeres y hombres. http:// ojs.uc.cl/index.php/bjur/article/view/829/847.

Connolly, William (1999). Why I am not a secularist [¿Por qué no soy un secularista?]. Minnesota University.

Consejo Episcopal Latinoamericano (2007). Documento Conclusivo de Aparecida. V Conferencia General del Episcopado Latinoamericano y del Caribe (2008). Discípulos y misioneros de Jesucristo para que nuestros pueblos en Él tengan vida. «Yo soy el Camino, la Verdad y la Vida» (Jn 14, 6). Paulinas. https://www.celam.org/aparecida/Espanol.pdf

Consejo Pontificio para la Familia (2004). Lexicón: Términos ambiguos y discutidos sobre familia, vida y cuestiones éticas. Editorial Palabra

Consejo Pontificio para los Laicos (18-03-2011). La Santa Sede denuncia un nuevo intento de imponer la ideología de género l'ideologia di genere. http://www.laici.va/content/laici/es/sezioni/donna/notizie/santa-sede-all-onu.html

Cooper, Melinda (2019). Family values: Between neoliberalism and the new social conservatism [Los valores familiares: entre el neoliberalismo y el nuevo conservadurismo social]. Massachusetts Institute of Technology.

Correa, Rafael (9-12-2014). El presidente Rafael Correa rechaza la ideología de género [Video]. YouTube. https://www. youtube.com/watch?v=wA2vkMZaG7s

Corrêa, Sonia (2018). A "política do gênero": um comentário genealógico [Las políticas de género: un comentario genealógico]. Cadernos Pagu, 53, e185301. https://doi.org/10.1590/18094449201800530001

Corrêa, Sonia y Isabela Kalil (2020). Políticas antigénero en America Latina: Brasil ¿La catástrofe perfecta? Observatorio de Sexualidad y Política. https://sxpolitics.org/GPAL/uploads/Ebook-Brasil\%2020200204.pdf

Deza, Soledad, Álvarez Mariana e Iriarte Alejandra (2014). Jaque a la reina: salud, autonomía y libertad reproductiva en Tucumán. Cienflores.

Facchini, Regina y Horacio Sívori (2017). Dossiê: Conservadorismo, direitos, moralidades e violência [Dossier: Conservadurismos, derechos, moralidades y violencias]. Cadernos Pagu, 50, e175000. http://dx.doi.org/10.1590/180 94449201700500000

Familia y Derechos Humanos. (1999). Pontificio Consejo para la Familia https://www.vatican.va/roman_curia/pontifical councils/family/documents/rc_pc_family_doc_20001115_family-human-rights_sp.html

Familia, Matrimonio y Uniones de Hecho. (2000). Pontificio Consejo para la Familia. https://www.vatican.va/roman curia/pontifical_councils/family/documents/rc_pc_family_doc_20001109_de-facto-unions_sp.html

Foucault, Michael (2007). Nacimiento de la biopolítica: Curso en el college de France (1978-1979) (Horacio Pons, Trad.). Fondo de Cultura Económica.

Francisco (19-03-2016). Exhortación apostólica postsinodal "Amoris laetitia" del Santo Padre Francisco sobre el amor en la familia. https://www.vatican.va/content/francesco/es/apost_exhortations/documents/papa-francesco_esortazioneap_20160319_amoris-laetitia.html

Habermas, Jürgen (2006). Entre naturalismo y religión (Pere Fabra et al., Trad.). Paidós.

Jakobsen, Janet R. y Anne Pellegrini (2004). Love the sin. Sexual regulation and the limits of religious tolerance [Ama al Pecado. La regulación sexual y los límites de la tolerancia religiosa]. Beacon.

Juan Pablo II. (1995, marzo), Carta Encíclica Evangelium Vitae. Valor e inviolabilidad de la vida humana. http://www. vatican.va/holy_father/john_paul_ii/encyclicals/documents/hf_jp-ii_enc_25031995_evangelium-vitae_sp.html

Kováts, Eszter y Maari Põim (Eds.) (2015). Gender as symbolic glue [El género como aglutinante simbólico]. Budapeste e Bruxelas. FEPS and Friedrich-Ebert-Stiftung.

Kuhar, Roman y David Paternotte (2017). Anti-Gender Campaigns in Europe: Mobilizing against Equality [Las campañas anti-género en Europa: movilización contra la igualdad]. Rowman \& Littlefield International.

Latinobarómentro. Opinión Pública Latinoamericana (2018). Informe Anual. https://www.latinobarometro.org/ latContents.jsp 
López Marina, Diego (3-05-2017). ¿Feminismo, ideología de género y pedofilia? Experto explica cómo se relacionan. ACI Prensa. https://www.aciprensa.com/noticias/feminismo-ideologia-de-genero-y-pedofilia-experto-explica-comose-relacionan-61916

Luna, Naara (2013). O direito à vida no contexto do aborto e da pesquisa com células tronco embrionárias: disputas de agentes e valores religiosos em um estado laico [El derecho a la vida en el contexto del aborto y de la investigación sobre células troncales-embrionarias: disputas de agentes y valores religiosos en un estado laico]. Religião e Sociedade, 33(1), 71-97. https://doi.org/10.1590/S0100-85872013000100005

Luna, Naara (2017). A criminalização da "ideologia de gênero": uma análise do debate sobre diversidade sexual na Câmara dos Deputados [La criminalización de la "ideología de género: un análisis del debate sobre la diversidad sexual en la Cámara de Diputados]. Cadernos Pagu (50), e175018. https://doi.org/10.1590/18094449201700500018

Marey, Macarena (2020) No tan distintos. El secularismo estatal, la politización eclesiástica y el imperativo del consenso. Revista Argentina de Ciencia Política, IIGG-FSOC-UBA, 24, pp. 45-69. https://publicaciones.sociales.uba.ar/index. php/revistaargentinacienciapolitica/article/view/5494/4479

Márquez, Nicolás y Laje, Agustín (2016). El libro negro de la nueva izquierda: ideología de género o subversión cultural. Grupo Unión, Centro de Estudios Libres.

Mayer, Sauer, B (2017). "Gender ideology" in Austria: Coalitions around an empty signifier [La "ideología de género" en Austria: Coaliciones bajo un significante vacío]. En Kuhar, R, Paternotte, D. (Eds.), Anti-gender campaigns in Europe: Mobilizing against equality (pp. 23-40). Rowman \& Littlefield.

Ministerio de Educación y Ciencias del Gobierno de Paraguay (2017). Resolución 29.664, por la cual se prohíbe la difusión y la utilización de materiales impresos como digitales, referentes a la teoría y/o ideología de género, en instituciones educativas dependientes del Ministerio de Educación y Ciencias. https://www.mec.gov.py/cms_v4/ documentos/ver documento/?titulo=29664-2017-RIERA1

Miskolci, Richard y Campana, Maximiliano (2017). "Ideologia de gênero": Notas para a genealogia de um pânico moral contemporáneo [La "ideología de género": notas para una genealogía del pánico moral contemporáneo]. Sociedade e Estado 32(3): 723-745. https://doi.org/10.1590/s0102-69922017.3203008

Morán Faúndes, José Manuel (2015). El desarrollo del activismo autodenominado "provida” en Argentina, 1980-2014. Revista mexicana de sociología, 77(3), 407-435. http://www.scielo.org.mx/scielo.php?script=sci_arttext\&pid=S018825032015000300003\&lng=es\&tlng=es.

Morán Faúndes, José Manuel (2019). The geopolitics of moral panic: the influence of Argentinian neo-conservatism in the genesis of the discourse of "gender ideology" [La geopolítica del pánico moral: la influencia del neoconservadurismo Argentino en la génesis del discurso de la 'ideología de género']. International Sociology, 34(4), 402-417. https://doi. org/10.1177/0268580919856488

Morán Faúndes, José Manuel y Peñas Defago, María Angélica (2013). ¿Defensores de la vida? ¿De cuál “vida”? Un análisis genealógico de la noción de "vida" sostenida por la jerarquía católica contra el aborto. Sexualidad, Salud y Sociedad, 15, 10-36. https://doi.org/10.1590/S1984-64872013000300002

Mouffe, Chantal (2002). Politics and passions. The stakes of democracy [Políticas y pasiones. Las apuestas de la democracia]. Centre for the Study of Democracy, University of Westminster.

O'Leary, Dale (1997). The gender agenda [La agenda del género]. Vital Issues.

Peker, Luciana (17-11-2018). La topadora antiderechos. Página|12. https://www.pagina12.com.ar/155698-la-topadoraantiderechos

Quack, Johannes (2014). Outline of a relational approach to 'nonreligion' [Esquema de un enfoque relacional sobre lo 'no religioso']. Method \& Theory in the Study of Religion, 26(4-5), 439-469. https://doi.org/10.1163/15700682-12341327

Romano, Silvina y Díaz Parra, Ibán (2018). Antipolíticas. Neoliberalismo, realismo de izquierda y autonomismo en América Latina. Luxemburg. http://iealc.sociales.uba.ar/wp-content/uploads/sites/57/2019/01/AntipoliticaseBook. pdf

Rubin, Gayle (1993). Thinking sex. Notes for a radical theory of the politics of sexuality [Reflexionando sobre el sexo. Notas para una teoría radical de la sexualidad]. En Abelove, H.; Barale, M. A.; Halperin, D. M. (Eds.), The lesbian and gay studies reader (pp. 3-44). Routledge.

Saez, Macarena (2016). La reglamentación del aborto en Chile: el fracaso de la separación entre Iglesia y Estado. En Macarena Saez y José Manuel Morán Faúndes (Eds.), Sexo, delitos y pecados intersecciones entre religión, género, sexualidad y el derecho en América Latina (pp.121-155). Center for Latin American \& Latino Studies American University.

Sales, Lilian y Mariano, Ricardo (2019). Ativismo político de grupos religiosos e luta por direitos [Activismo político de grupos religiosos y lucha por los derechos]. Religião \& Sociedade, 39(2), 9-27. https://doi.org/10.1590/0100$85872019 v 39$ n2editorial

Scala, Jorge (2001). Género y Derechos Humanos. Vórtice. https://www.pj.gov.py/ebook//monografias/extranjero/ derechos-humanos/Jorge-Scala-Género-y-Derechos-Humanos.pdf

Scott, Joan Wallach (2018). Sex and Secularism. Princeton University.

Sgró Ruata, María Candelaria; Vaggione, Juan Marco (2017). El Papa Francisco I y la sexualidad: políticas de dislocación. Revista Mexicana de Ciencias Políticas y Sociales, 63(232), 153-180. http://dx.doi.org/10.22201/ fcpys. $2448492 x e .2018 .232 .57338$ 
Souroujon, Gastón (2019). Los imaginarios de la centroderecha argentina. Entre el primer mundo y la autoayuda. Reflexión Política, 21(42), 129-143. https://doi.org/10.29375/01240781.3326

Souroujón, Gastón (2021). El aborto la manzana de la discordia de la nueva derecha. Los argumentos liberales y conservadores de los diputados del PRO. Revista Mexicana de Ciencias Políticas y Sociales, 66(243), $141-162$. https://dialnet.unirioja.es/servlet/articulo?codigo $=8088022$

Teixeira, Raniery (2019). Ideologia de Gênero? As reações à agenda política de igualdade de gênero no Congresso Nacional [¿Ideología de Género? Las reacciones a la agenda política de la igualdad de género en el Congreso Nacional]. Disertación, Universidad de Brasilia.

TELAM (03-08-2016). Francisco señaló a la “teoría de género” como herramienta de “colonización ideológica. ” https:// www.telam.com.ar/notas/201608/157624-papa-francisco-teoria-genero-colonizacion-ideologica-paises-influyentesdiversidad-sexual.html

Vaggione, Juan M. y Machado, María das Dores (2020). Religious patterns of neoconservatism in Latin America [Los patrones religiosos del neoconservadurismo en América Latina]. Politics \& Gender, 16(1), E2. https://doi.org/10.1017/ S1743923X20000082

Vaggione, Juan Marco (2005). Reactive politicization and religious dissidence. The political mutations of the religious [La politización Reactiva y la Disidencia Religiosa. Las mutaciones políticas de lo religioso]. Social Theory and Practice, 31(2), 233-255.

Vaggione, Juan Marco (2020). A restauração legal: o neoconservadorismo e o direito na América Latina [La restauración legal: el neoconservadurismo y el derecho en América Latina]. En Flávia Biroli, Maria das Dores Campos Machado, Juan Marco Vaggione (Eds.), Gênero, neoconservadorismo e democracia. Disputas e retrocessos na América Latina. Boitempo.

Vaggione, Juan Marco y José Manuel Morán Faúndes (2021). Neoconservative incursions into party politics: The cases of Argentina and Chile [Las incursiones neoconservadoras en la política partidaria: los casos de Argentina y Chile]. En Barbara Sutton, Nayla Luz Vacarezza (Eds.). Abortion and Democracy. Contentious Body Politics in Argentina, Chile, and Uruguay (pp. 93-114). Routledge.

Viveros Vigoya, Mara y Rodríguez Rondón, Manuel Alejandro (2017). Presentación. Hacer y deshacer la ideología de género. Sexualidad, Salud y Sociedad. Revista Latinoamericana, 27. https://doi.org/10.1590/1984-6487. sess.2017.27.07.a.

Zamberlin, Nina (2015). El estigma asociado al aborto como objeto de estudio: los primeros pasos en América Latina en Ramos, S. (org.). Investigación sobre aborto en América Latina y el Caribe: una agenda renovada para informar políticas públicas e incidencia. Centro de Estudios de Estado y Sociedad. 